\title{
Modelo Virtual Tridimensional de la Articulación Cubital del Perro a Partir de Cortes Plastinados Ultradelgados
}

\author{
Three-Dimensional Virtual Model of the Elbow Joint \\ of the Dog by Means of Ultrathin Plastinated Slices
}

\author{
Jorge Arredondo*; Octavio López-Albors**; Sergio Recillas ${ }^{* * * *}$; Mauro Victoria***; \\ Octavio Castelán"; Manuel González-Ronquillo*; Sigrid Becerril" \& Rafael Latorre**
}

ARREDONDO, J.; LÓPEZ-ALBORS, O.; RECILLAS, S.; VICTORIA, M.; CASTELÁN, O.; GONZÁLEZ-RONQUILLO, M.; BECERRIL, S. \& LATORRE, R. Modelo virtual tridimensional de la articulación cubital del perro a partir de cortes plastinados ultradelgados. Int. J. Morphol., 34(4):1253-1258, 2016.

RESUMEN: La articulación cubital del perro es de tipo compuesta, formada por el cóndilo del húmero, la cabeza del radio y la escotadura troclear de la ulna. Esta articulación es propensa a padecer enfermedades del desarrollo, lesiones traumáticas y degenerativas. La corrección de estos padecimientos suele ser quirúrgica, sin embargo, el planteamiento de la cirugía resulta difícil debido a la complejidad estructural de esta articulación. Los modelos anatómicos tridimensionales (3D) obtenidos de los cortes seriados mediante tomografía computarizada han probado ser eficaces en el planteamiento de los abordajes quirúrgicos, sin embargo tiene limitaciones técnicas en la identificación de los tejidos blandos. Los cortes ultradelgados (1 mm) obtenidos mediante plastinación permiten realizar descripciones anatómicas detalladas de regiones anatómicas complejas y también pueden ser usadas para realizar reconstrucciones 3D. El objetivo del presente trabajo, ha sido obtener una reconstrucción 3D de las estructuras anatómicas que conforman el codo del perro a partir de cortes plastinados ultradelgados.

PALABRAS CLAVE: Codo, Plastinación, Modelo Tridimensional.

\section{INTRODUCCIÓN}

La articulación cubital es de tipo sinovial compuesta, formada por las articulaciones humeroulnar, humeroradial y radioulnar proximal (Budras, 2007; Adams, 2004; Sandoval, 1998). Esta articulación está cubierta en toda su periferia por una cápsula articular, la cual en el perro está reforzada por los ligamentos colateral cubital, lateral y medial, el ligamento oblicuo, el ligamento anular del radio y el ligamento del olécranon (Getty, 1982; Sandoval, 1998). Las estructuras articulares del codo son objetivo de múltiples lesiones traumáticas, degenerativas y del desarrollo en el perro, destacándose la alta incidencia de displasia del codo en perros jóvenes de talla grande (Padgett et al., 1995). En la actualidad, la discusión científica se centra en el planteamiento de mejores opciones terapéuticas y en la explicación a los fenómenos fisiopatológicos que afectan a esta articulación, para cum- plir con lo anterior, el desarrollo de modelos anatómicos bidimensionales y tridimensionales ofrecen la oportunidad de conocer a detalle la interacción de los sistemas muscular y esquelético (Bockstahler, 2011). Los cortes seccionales plastinados permiten realizar modelos tridimensionales (3D) de las estructuras anatómicas (Sora, 2007). Estas reconstrucciones tridimensionales son útiles para observar la correcta relación topográfica entre las estructuras anatómicas que conforman una región específica del cuerpo, por lo que resultan de gran utilidad para el estudio en detalle de la anatomía, así como para plantear nuevos abordajes quirúrgicos que faciliten la recuperación posquirúrgica y minimicen los riesgos iatrogénicos. El objetivo del presente trabajo ha sido crear un modelo 3D del codo del perro a partir de cortes anatómicos plastinados ultradelgados.

\footnotetext{
* Cuerpo Académico en Ciencia e Innovación Tecnológica Pecuaria, Universidad Autónoma del Estado de México.

** Departamento de Anatomía y Anatomía Patológica Comparadas, Universidad de Murcia, España.

**** Cuerpo Académico en Innovación en Anestesiología, Farmacología y Cirugía Aplicada a las Ciencias Médico Veterinarias de la Universidad Autónoma del Estado de México.

Este trabajo ha sido financiado por el Programa de Mejoramiento del Profesorado (PROMEP) de la Secretaría de Educación Pública de México. FE013 (103.5/10/4368)
} 
ARREDONDO, J.; LÓPEZ-ALBORS, O.; RECILLAS, S.; VICTORIA, M.; CASTELÁN, O.; GONZÁLEZ-RONQUILLO, M.; BECERRIL, S. \& LATORRE, R. Modelo virtual tridimensional de la articulación cubital del perro a partir de cortes plastinados ultradelgados. Int. J. Morphol., 34(4):1253-1258, 2016.

\section{MATERIAL Y MÉTODOS}

Para el presente estudio se empleó un cadáver de perro raza Pastor Alemán, de $30 \mathrm{~kg}$ de peso vivo, macho el cual se obtuvo del Animalario de la Universidad de Murcia y había sido eutanasiado por razones diferentes al presente estudio. La integridad de la articulación se valoró mediante dos proyecciones radiográficas: craneocaudal y mediolateral. Con la finalidad de observar con mayor detalle las estructuras arteriales relacionadas con la articulación cubital se realizó la inyección intravascular de epoxi rojo (Araldit ${ }^{\circledR}$ CY 223 Uneco $^{\circledR}$ y Aradur ${ }^{\circledR}$ HY 2967 Uneco $^{\circledR}$ ) a través de la arteria braquial. Posteriormente se congeló el cadáver a $-24^{\circ} \mathrm{C}$ por 72 horas y se seccionó el bloque conteniendo a la articulación cubital a nivel del tercio distal de la diáfisis del húmero y hasta el tercio proximal de la diáfisis del radio empleando una sierra de cinta de alta velocidad. El bloque del codo se plastinó empleando la técnica E12-E6-E600 (Sora) y se cortó de manera seriada en su plano transversal empleando una sierra de diamante $\left(\right.$ Exakt $^{\circledR}$, Alemania) con un espesor de $1 \mathrm{~mm}$ para cada corte.

Los cortes fueron digitalizados por su cara proximal, empleando un escáner (Epson ${ }^{\circledR}$ Perfection 610) y posteriormente las imágenes fueron cargadas en el programa informático Winsurf ${ }^{\circledR}$ (Surfdriver software) con la finalidad de trazar las estructuras anatómicas que conforman a la articulación del codo y las relacionadas a ella. Una vez terminado el trazado se realizó la renderización volumétrica tridimensional.

\section{RESULTADOS}

La plastinación ha sido empleada para responder diferentes cuestiones de anatomía clínica. La técnica de plastinación E12-E6-E600 permitió obtener cortes plastinados ultradelgados los cuales mostraron de manera precisa las estructuras óseas, articulares, musculares y vasculares de la articulación cubital permitiendo establecer las relaciones topográficas existentes entre ellas, así como también permitieron observar la dirección de las fibras musculares (Fig. 1A-B). Todas las estructuras fueron fácilmente identificadas lo que favoreció el trazado de los márgenes de cada una de ellas. La importancia de comprender a detalle la anatomía seccional se pone de manifiesto durante la interpretación de las técnicas de diagnóstico tomográficas como son la ecografía, la tomografía computarizada y la imagen por resonancia magnética.
La reconstrucción volumétrica de los cortes plastinados derivó en un modelo anatómico 3D de la articulación cubital del perro el cual representó tejidos reales y mostró una morfología clara, equiparable con un modelo cadavérico (Fig. 1C-F). Además, el modelo pudo ser girado libremente en todas las direcciones facilitando la identificación de las diferentes estructuras que lo conforman, cada una de las cuales pudo ser coloreada en diferentes tonos, así también permitió realizar ajustes de su transparencia o la sustracción completa para observar otras estructuras adyacentes. Este modelo 3D mostró a todas las estructuras reconstruidas en conjunto ó de manera individual lo cual favoreció el análisis y estudio morfológico.

\section{DISCUSIÓN}

La descripción anatómica detallada de la articulación cubital del perro es indispensable para comprender los procesos patológicos que afectan a esta articulación, así como para interpretar de manera precisa las imágenes necesarias para integrar un diagnóstico preciso. La reconstrucción 3D obtenida en el presente trabajo ha permitido observar detalles precisos de la anatomía articulación cubital del perro así como de las estructuras relacionadas a está.

La reconstrucción tridimensional confirmó la complejidad estructural de la articulación cubital del perro, en ella se pudieron observar las tres articulaciones que lo conforman (Ruberte \& Sautet 1996; Sandoval; Adams; Budras ). Así también, permitió mostrar a detalle las superficies articulares y la relación topográfica que guardan entre sí (Aspinall \& O’Reilly, 2007). Estas articulaciones están envueltas en una sola cápsula articular (Adams; Aspinall \& O’Reilly)

\section{Superficies articulares}

Los detalles anatómicos específicos de las superficies articulares se destacan en la reconstrucción tridimensional, de esta forma, pudimos constatar la división del cóndilo humeral en una tróclea y una cabeza, las cuales se observaron articuladas con el ulna y el radio respectivamente (Sandoval; Dyce, 2007). Los procesos coronoideas localizadas en posición lateral y medial respecto a la incisura radial son observados en una vista ventral de nuestro estudio (Schwarze, 1984). 

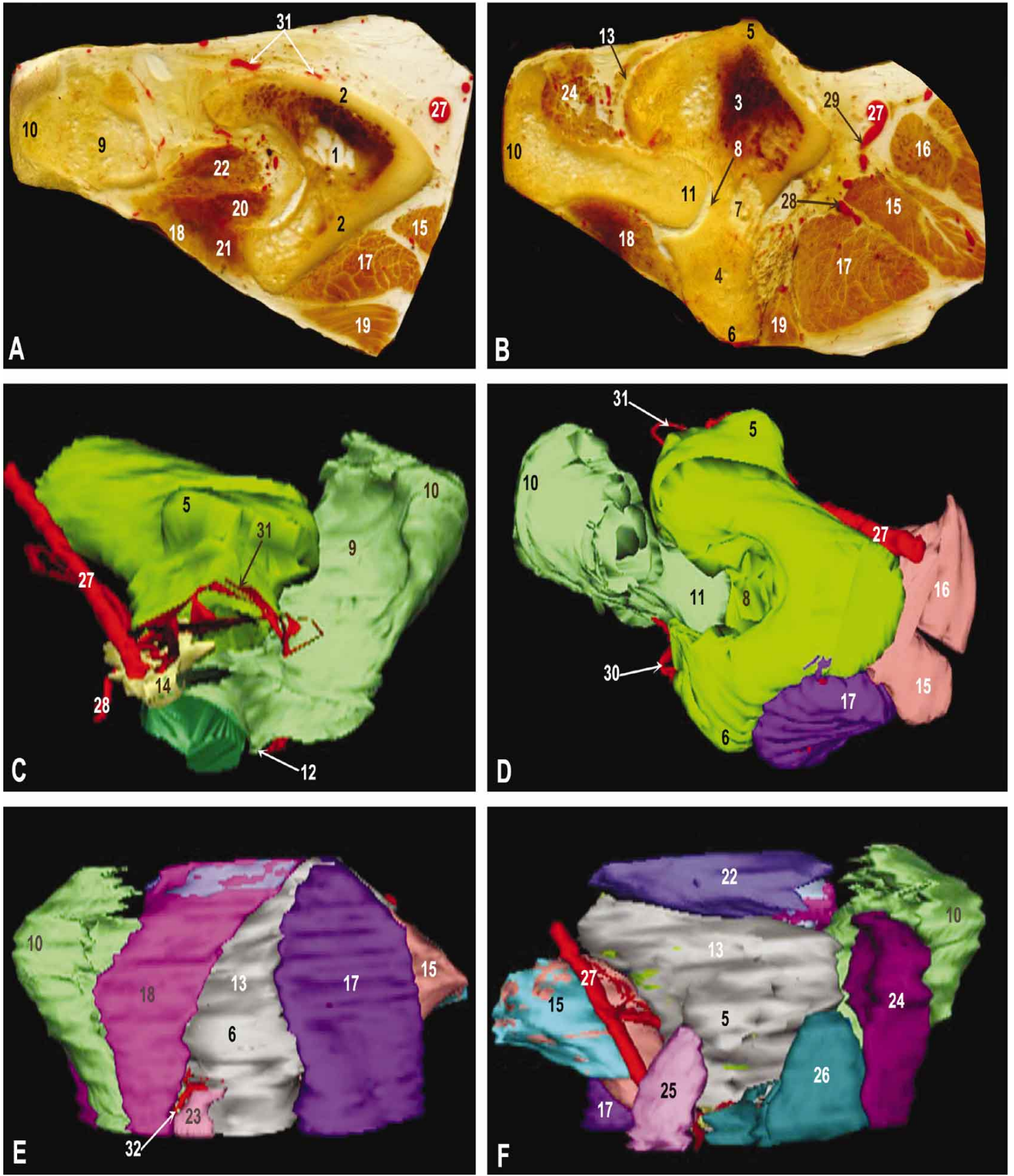

Fig. 1. Anatomía seccional y reconstrucción tridimensional de la articulación cubital del perro. (A) Cortes ultrafinos transversales plastinados (E12-E6-E600) a nivel del olécranon y (B) del proceso ancóneo. Vistas (C) medial oblicua $10^{\circ}$ (se han sustraido todas las estructuras musculares y la cápsula articular); (D) dorsal; (E) lateral y (F) medial (se ha sustraído el músculo flexor carpo radial) de la reconstrucción tridimensional: 1. Médula de la diáfisis del húmero. 2. Corticales de la díafisis del húmero. 3. Tróclea del cóndilo. 4. Cabeza del cóndilo. 5. Epicóndilo medial. 6. Epicóndilo lateral. 7. Fosa radial. 8. Fosa del olécranon. 9. Olécranon. 10. Tuberosidad del olécranon. 11. Proceso ancónea 12. Proceso coronoideo medial. 13. Cápsula articular. 14. Ligamento anular del radio. 15. Músculo bíceps braquial 16. Músculo pectoral transverso. 17. Músculo braquial. 18. Músculo ancóneo. 19. Músculo extensor carpo radial. 20. Músculo tríceps braquial (cabeza accesoria). 21. Músculo tríceps braquial (cabeza lateral). 22. Músculo tríceps braquial (cabeza medial). 23. Músculo extensor carpo ulnar. 24. Músculo flexor carpo ulnar. 25. Músculo pronador redondo. 26. Músculo flexor digital superficial. 27. Arteria braquial. 28. Arteria bicipital. 29. Arteria transversa cubital. 30. Arteria recurrente ulnar. 31. Arteria colateral ulnar. 32. Arteria braquial profunda. 
En lo referente a las superficies articulares, la tróclea del húmero la observamos en la región caudal de la articulación del cubito y la superficie articular distal del húmero presentando una superficie articular en forma de tróclea (Getty; Dyce). Se observó en detalle el proceso ancóneo como una proyección de la incisura troclear del ulna (König \& Liebich, 2009).

\section{Cápsula articular}

Nuestros resultados mostraron la presencia de la cápsula articular única que rodea a la articulación del codo (Getty; Williams et al., 1985; Nickel et al., 1986) la cual se inserta a cada lado de la ulna dentro de la fosa del olécranon y se extiende distalmente en una corta distancia entre el ulna y radio (Dyce).

Nuestros resultados fueron muy detallados al mostrar el riego vascular de la cápsula articular a través de la arteria colateral ulnar (Getty), la arteria transversa cubital y la arteria braquial profunda (Sandoval), lo cual debe tomarse en cuenta durante el abordaje quirúrgico de la articulación del cubito.

La descripción detallada de las reconstrucciones presentadas en este trabajo nos ha permitido conocer la topografía de la cápsula articular, así como su relación con estructuras musculares, vasculares y nerviosas, lo cual representa un significado clínico y quirúrgico importante.

\section{Ligamentos}

En nuestro estudio se pudo observar al ligamento anular del radio rodeando a la cabeza del radio y formando un anillo al insertarse en el proceso coronoideo medial (Sandoval, Adams; Dyce). Aunque en la reconstrucción no fue posible observar la inserción que realiza en el ligamento colateral cubital lateral (Sandoval).

Nuestro estudio mostró la posición del ligamento colateral cubital lateral originándose en el epicóndilo lateral del húmero y en una posición craneal al músculo extensor carpo radial y caudal al músculo extensor carpo ulnar. Aunque no fue posible observar a detalle el total de sus inserciones descritas por Köning \& Liebich y Dyce. Así también, el ligamento colateral cubital medial se observó alargado y delgado (Dyce), originándose en el epicóndilo medial del húmero y relacionándose medialmente con el músculo flexor digital profundo y caudalmente al músculo flexor carpo ulnar, además se observo medial a la incisura radial. Respector a este ligamento solo nos fue posible observar la inserción caudal al ulna, descrita por Gil et al. (2005) y por Köning \& Liebich.

\section{Vascularización}

La reconstrucción tridimensional permitió observar con gran detalle las relaciones topográficas de las arterias con otras estructuras anatómicas relevantes, lo que permite establecer de manera precisa su localización y por lo tanto disminuir el riesgo de lesión iatrogénica durante los procedimientos quirúrgicos que afecten a esta articulación.

La factibilidad de realizar sustracciones de las estructuras en la reconstrucción tridimensional permitió identificar de manera precisa las ramas arteriales relacionadas a esta articulación, de esta forma, al sustraer al músculo bíceps braquial, se identificó la trayectoria de la arteria braquial en posición craneal a la tróclea del húmero (Dyce) y al sustraer el músculo braquial de la reconstrucción, se observó la posición de la arteria braquial en relación craneal al epicóndilo lateral del húmero, en el conocimiento de los autores esta relación no había sido descrita anteriormente.

En el estudio se observó en detalle la arteria profunda braquial, su trayecto hacia la mitad del húmero, inmediatamente distal a la inserción del músculo redondo mayor (Sandoval) y la estrecha relación con el músculo ancóneo en su porción media así como su respectiva irrigación (Schwarze, 1972; Getty). Consideramos que la información anterior puede ser de utilidad como referencia para abordajes ortopédicos de esta articulación.

Nuestro estudio mostró la posición de la arteria colateral ulnar discurriendo caudalmente y ramificándose a nivel del olécranon en posición cercana al nervio ulnar. Así también, fue posible observar su posición en relación a los músculos caudales del antebrazo (Sandoval).

Se observó el origen de la arteria bicipital emergiendo de la arteria braquial. Nuestro estudio mostró también su trayecto en un punto cercano a la superficie craneal de la diáfisis del húmero donde alcanza al músculo bíceps braquial para irrigarlo (Sandoval).

Para poder observar la trayectoria de la arteria cubital transversa en su porción craneal se retiró el músculo pronador redondo. Nuestros resultados coinciden con lo descrito anteriormente por Gil et al. quienes mencionan que ésta se localiza entre la cara flexora de la articulación cubital y el músculo bíceps braquial. La reconstrucción mostró el punto donde se origina la arteria braquial a nivel del cóndilo humeral, adyacente a la superficie medial de la cápsula de la articulación cubital, a la que vasculariza (Sandoval). 


\section{Músculos relacionados con la articulación cubital}

El estudio anatómico tridimensional de la articulación cubital permitió establecer las relaciones topográficas de la musculatura estabilizadora de esta articulación, además, mediante la sustracción digital de las imágenes se pudieron observar con gran detalle la proximidad entre los diferentes músculos. El conocer a detalle estas relaciones topográficas tiene un gran interés a nivel de la fisiopatología de las enfermedades del codo y una gran importancia en el planteamiento de abordajes quirúrgicos a esta articulación

La división de los grupos musculares en grupo braquial y grupo antebraquial facilitó la comprensión de sus relaciones topográficas.

En la reconstrucción observamos con precisión a los músculos que conforman el grupo braquial y sus relaciones entre sí. La última porción del músculo braquial fue identificada en su punto de inserción, localizándose en posición craneal respecto a la diáfisis del húmero (Sandoval; König \& Liebich) y al músculo ancóneo cubriendo la parte lateral del olécranon en relación caudal a la fosa olecraneana (Sandoval; Gil et al.; Budras et al.).

La reconstrucción permitió observar las cuatro cabezas del músculo tríceps braquial relacionadas al aspecto caudal, lateral y medial del húmero e insertándose en un punto común a nivel del olécranon.

La topografía de los músculos del grupo antebraquial fue descrita con precisión, lo cual se facilitó por la función de sustracción digital de las estructuras anatómicas en la reconstrucción.

La reconstrucción tridimensional de la articulación cubital del perro facilitó la localización de los músculos del grupo antebraquial debido a la posibilidad de poder realizar sustracción de los tejidos anatómicos eliminando la sobreposición de las estructuras musculares.

En una vista lateral se observó al músculo extensor carpo radial de mayor tamaño y craneal en relacion a los otros músculos extensores de la articulación del carpo. No nos fue posible observar su origen, pero si parte de su trayectoria craneal al radio: entre el músculo braquial y el músculo extensor digital común (Sandoval).

El músculo extensor digital común, se observo fusiforme entre los músculo extensores carpo radial y digital común . El origen lo pudimos observar más preciso en el epicóndilo lateral del húmero, inmediatamente proximal al ligamento colateral cubital lateral (Sandoval; Budras et al.; Gil et al.).
En el plano superficial de la vista medial se identificó al músculo pronador redondo en posición craneal al epicóndilo medial del húmero, también se observó su inserción en el margen medial del tercio proximal del radio de acuerdo con Sandoval y Gil et al.

El músculo flexor carpo radial se localizó en posición caudal al músculo pronador redondo y caudomedial al radio, de igual forma pudimos observar su origen en el epicóndilo medial del húmero (Sandoval y Gil et al.).

El músculo flexor digital superficial se observó cubriendo la cara medial de la tróclea del húmero prolongándose a lo largo de la región del antebrazo. Pudimos observar el origen en el epicóndilo medial del húmero (Sandoval y Budras et al.).

\section{CONCLUSIóN}

El modelo 3D mostró a las estructuras anatómicas de una manera precisa sin perder las relaciones topográficas entre ellas. Este modelo permitió ser manipulado digitalmente para observar los detalles anatómicos desde diferentes perspectivas, lo cual puede ser de gran utilidad en la planificación de abordajes convencionales o en el desarrollo de nuevas estrategias quirúrgicas.

ARREDONDO, J.; LÓPEZ-ALBORS, O.; RECILLAS, S.; VICTORIA, M.; CASTELÁN, O.; GONZÁLEZRONQUILLO, M.; BECERRIL, S. \& LATORRE, R. Threedimensional virtual model of the elbow joint of the dog by means of ultrathin plastinated slices. Int. J. Morphol., 34(4):1253-1258, 2016.

SUMMARY: The dog's elbow joint is a very complex structure formed between the humeral condyle, the radial head and the ulnar trochlear notch. This joint is prone to suffer growth disorders, traumatic injuries, and degenerative conditions. All these problems used to be solved by surgical means, nevertheless, the surgical plan, results in a complex decision making process related with the aforementioned joint characteristics, three dimensional (3D) anatomical models from computed tomography have proven to be useful in the surgical approach, nevertheless the image technique is at some point limited, mainly identifying soft tissues. Ultrathin plastinated slices $(1 \mathrm{~mm})$ allows to perform very detailed descriptions of complex structures and 3D reconstructions as well. The aim of this work, was to obtain a 3D reconstruction of ultrathin plastinated elbow joint in the dog.

KEY WORDS: Elbow; Plastination; Three-Dimensional Model. 


\section{REFERENCIAS BIBLIOGRÁFICAS}

Adams, D. Canine Anatomy, A systemic Study. $4^{\text {th }}$ ed. Blackwell Publishing Company, 2004.

Aspinall, V. \& O’reilly, M. Introducción a la Anatomía y Fisiología Veterinarias, Acribia, 2007.

Bockstahler, B. The canine elbow: A joint in the focus of research. Vet. J., 190(2):189-90, 2011.

Budras, K. D.; McCarthy, P.; Fricke, W. \& Richter, R. Anatomy

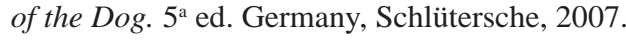

Dyce, K. M. Anatomía Veterinaria. $3^{\mathrm{a}}$ ed. México, Manual Moderno, 2007.

Getty, R.; Sisson \& Grossman: Anatomía de los animales domésticos. $5^{\mathrm{a}}$ ed. Tomo II. Mexico, Salvat, 1982.

Gil, J.; Gimeno, M.; Laborda, J. \& Nuviala, J. Protocolos de disección. $2^{\text {a }}$ ed. Barcelona, Masson, 2005.

König, H. \& Liebich, H. Veterinary Anatomy of Domestic Mammals. $4^{\text {a }}$ ed. Germany, Schattaur, 2009.

Nickel, R.; Schummer, A. \& Seiferle, E. The Anatomy of the Domestic Animals. Vol 1, The Locomotor System of the Domestic Mammals. Verlag Paul Parey, 1986.

Padgett, G.A.; Mostosky, U.V.; Probst, C.W.; Thomas, M.W. \& Krecke, C.F. The inheritance of osteochondritis dissecans and fragmented coronoid process of the elbow joint in labrador retrievers. J. Am. Anim. Hosp. Assoc., 31(4):327-30, 1995.

Ruberte, J.; Sautet, J. Atlas de Anatomía del Perro y del Gato. Volumen 2. Tórax y Miembro Torácico. Multimedica, 1996.

Sandoval, J. Tratado de Anatomía Veterinaria. Tomo II. Aparato Locomotor. $3^{\text {a }}$ ed. Barcelona, Sorles, 1998.

Schwarze, E. Compendio de anatomía Veterinaria, Introducción a la anatomía veterinaria, aparato locomotor. Barcelona, Acribia, 1984.

Schwarze, E. Compendio de anatomía Veterinaria. Tomo III Aparato circulatorio y piel. Madrid, Acribia, 1972.

Sora, M. Epoxy Plastination of biological tissue: E12 Ultra-thin Technique. J. Int. Soc. Plastination, 22:40-5, 2007.

Williams, P. \& Warwick, R. Gray Anatomía. Tomo II. Barcelona, Salvat, 1985.
Dirección para correspondencia: Jorge Arredondo Cuerpo Académico en Ciencia e Innovación Tecnológica Pecuaria Universidad Autónoma del Estado de México Toluca

MÉXICO

E-mail: arredondo.uaemex@gmail.com

Recibido : 07-03-2016

Aceptado: 11-08-2016 